\title{
Roflumilast promotes memory recovery and attenuates white matter injury in aged rats subjected to chronic cerebral hypoperfusion
}

Citation for published version (APA):

Santiago, A., Soares, L. M., Schepers, M., Milani, H., Vanmierlo, T., Prickaerts, J., \& de Oliveira, R. M. (2018). Roflumilast promotes memory recovery and attenuates white matter injury in aged rats subjected to chronic cerebral hypoperfusion. Neuropharmacology, 138, 360-370.

https://doi.org/10.1016/j.neuropharm.2018.06.019

Document status and date:

Published: 01/08/2018

DOI:

10.1016/j.neuropharm.2018.06.019

Document Version:

Publisher's PDF, also known as Version of record

Document license:

Taverne

Please check the document version of this publication:

- A submitted manuscript is the version of the article upon submission and before peer-review. There can be important differences between the submitted version and the official published version of record.

People interested in the research are advised to contact the author for the final version of the publication, or visit the DOI to the publisher's website.

- The final author version and the galley proof are versions of the publication after peer review.

- The final published version features the final layout of the paper including the volume, issue and page numbers.

Link to publication

\footnotetext{
General rights rights.

- You may freely distribute the URL identifying the publication in the public portal. please follow below link for the End User Agreement:

www.umlib.nl/taverne-license

Take down policy

If you believe that this document breaches copyright please contact us at:

repository@maastrichtuniversity.nl

providing details and we will investigate your claim.
}

Copyright and moral rights for the publications made accessible in the public portal are retained by the authors and/or other copyright owners and it is a condition of accessing publications that users recognise and abide by the legal requirements associated with these

- Users may download and print one copy of any publication from the public portal for the purpose of private study or research.

- You may not further distribute the material or use it for any profit-making activity or commercial gain

If the publication is distributed under the terms of Article 25fa of the Dutch Copyright Act, indicated by the "Taverne" license above, 


\title{
Roflumilast promotes memory recovery and attenuates white matter injury in aged rats subjected to chronic cerebral hypoperfusion
}

\author{
Amanda Santiago a, 1 , Lígia Mendes Soares ${ }^{\text {a, }}{ }^{\text {, }}$, Melissa Schepers ${ }^{\text {b, c }}$, Humberto Milani a \\ Tim Vanmierlo ${ }^{\mathrm{b}, \mathrm{c}}$, Jos Prickaerts ${ }^{\mathrm{b}}$, Rúbia M. Weffort de Oliveira ${ }^{\mathrm{a}, *}$ \\ a Department of Pharmacology and Therapeutics, State University of Maringá, Av. Colombo, 5790, CEP 87020-900, Maringá, Paraná, Brazil \\ b Department of Psychiatry and Neuropsychology, School for Mental Health and Neuroscience, Maastricht University, Maastricht, The Netherlands \\ c Department of Immunology and Biochemistry, Biomedical Research Institute, Hasselt University, Hasselt, Belgium
}

\section{A R T I C L E I N F O}

\section{Article history:}

Received 21 August 2017

Received in revised form

24 April 2018

Accepted 14 June 2018

Available online 19 June 2018

\section{Keywords:}

Phosphodiesterase inhibitor

Roflumilast

Chronic cerebral hypoperfusion

Memory

\begin{abstract}
A B S T R A C T
Chronic cerebral hypoperfusion $(\mathrm{CCH})$ has been associated with aging-related vascular dementia, including Alzheimer's disease. It can be induced by the four-vessel occlusion/internal carotid artery (4VO/ICA) model in aged rats, resulting in persistent memory deficits, white matter injury, and significant neuronal loss in the hippocampus and cerebral cortex. The phosphodiesterase type 4 inhibitor (PDE4-I) roflumilast has been reported to have pro-cognitive effects in several behavioral paradigms. The present study evaluated the effects of repeated roflumilast treatment in aged rats that were subjected to $\mathrm{CCH}$. After surgery, roflumilast $(0.003$ and $0.01 \mathrm{mg} / \mathrm{kg})$ was administered intraperitoneally once per day for 29 days. Memory performance was assessed in the aversive radial maze (AvRM) 7, 14, and 21 days after $\mathrm{CCH}$. The effects of roflumilast on hippocampal neurodegeneration and white matter injury were investigated using Nissl and Kluver-Barrera staining, respectively. Western blot and RT-qPCR were used to explore microglial polarization using M1 (Iba-1 and iNOS) and M2 (Arginase-1) markers. Chronic cerebral hypoperfusion caused persistent memory deficits, hippocampal neurodegeneration, and vacuolization and fiber disarrangement in white matter. Repeated roflumilast treatment restored $\mathrm{CCH}-$ induced cognitive impairments in aged rats but in the absence of the rescue of hippocampal neurons. Attenuation of white matter injury was detected in the optic tract in aged $\mathrm{CCH}$ rats that were treated with roflumilast. In vitro, roflumilast increased Arg-1 gene expression in myelin-laden primary microglia. The present data suggest that roflumilast might be useful for the treatment of cognitive sequelae associated with $\mathrm{CCH}$.
\end{abstract}

(c) 2018 Published by Elsevier Ltd.

\section{Introduction}

Phosphodiesterases (PDE) are enzymes responsible for the breakdown of cyclic nucleotides cyclic adenosine monophosphate (cAMP) and cyclic guanosine monophosphate (cGMP) into their respective inactive forms (Conti and Beavo, 2007). These cyclic nucleotides are ubiquitous second messenger molecules with important roles in relaying incoming signals at the neurons to downstream effectors which enhance synaptic plasticity (Frey et al., 1993; Son et al., 1998; Prickaerts et al., 2002). The PDE family includes different subfamilies (PDE1-PDE11), each with their specific

\footnotetext{
* Corresponding author.

E-mail address: rmmwoliveira@uem.br (R.M. Weffort de Oliveira).

1 These authors contributed equally to this study.
}

function, regulation and localization pattern (Bender and Beavo, 2006). PDE4 selectively catalyzes the hydrolysis of cAMP, which in turn activates protein kinase A (PKA) and cAMP response element binding (CREB) protein (Conti and Beavo, 2007). Four genes encode different PDE4 enzymes. PDE4A, PDE4B, and PDE4D but not PDE4C are expressed in the central nervous system (CNS; Menniti et al, 2006). PDE4 is highly expressed in the hippocampus and cerebral cortex (Braun et al., 2007) and has been shown to be involved in signaling cascades that mediate learning and memory processes (Rose et al., 2005; Li et al., 2011; Peng et al., 2014; Heckman et al., 2015).

Experimental evidence indicates that PDE4 inhibition may be a novel approach for treating several brain disorders, such as depression (e.g., O'Donnell and Zhang, 2004), anxiety (e.g., Li et al., 2009), schizophrenia (e.g., Garcia et al., 2016), Alzheimer's disease (Cheng et al., 2010), and multiple sclerosis (Gonzalez-Garcia et al., 
2013). PDE4 inhibition has also been shown to play an important role in cognitive function (Bender and Beavo, 2006). For example, the prototypical PDE4 inhibitor (PDE4-I) rolipram improved memory in healthy rats (Rutten et al., 2006) and reversed memory deficits that were induced by scopolamine (Imanishi et al., 1997), MK-801 (Zhang and O'Donnell, 2000; Rutten et al., 2007), and A $\beta$ protein (Gong et al., 2004; Zhuo et al., 2016) in rodents. Rolipram also improved spatial memory in aged rats that presented hypertension (Jabaris et al., 2015a). In models of brain ischemia, rolipram improved memory and emotional deficits, decreased the size of the infarcted area, and attenuated neuronal damage in the hippocampus (Block et al., 1997; Nagakura et al., 2002; Li et al., 2011; Soares et al., 2016). However, rolipram also produces severe side effects in humans, such as nausea and emesis, which limit its clinical use (Rock et al., 2009).

Roflumilast is a second-generation selective PDE4-I with fewer emetic properties. It has been approved by the United States Food and Drug Administration (FDA) for the treatment of peripheral inflammatory disease and severe chronic obstructive pulmonary disease (COPD; Rabe, 2011; Tashkin, 2014). Recently, it was demonstrated memory improvement after acute roflumilast administration in young, healthy subjects tested on the verbal learning task (Van Duinen et al., 2018). Roflumilast was also shown to ameliorate memory performance in rodents in several behavioral paradigms (Jabaris et al., 2015a, 2015b; Vanmierlo et al., 2016). When combined with a subeffective dose of donepezil, a subeffective dose of roflumilast completely restored memory deficits that were induced by the muscarinic receptor antagonist scopolamine in rats (Vanmierlo et al., 2016). To our knowledge, the effects of roflumilast on conditions of cerebrovascular ischemic diseases have not yet been investigated.

Chronic cerebral hypoperfusion $(\mathrm{CCH})$ is an ischemic state whereby cerebral blood flow is gradually and permanently reduced. It has been associated with neurodegenerative conditions, including aging-related vascular dementia and Alzheimer's disease (De la Torre, 2009; Zhao et al., 2014). Chronic cerebral hypoperfusion can be induced by the four-vessel occlusion/internal carotid artery (4VO/ICA) model in aged rats, resulting in persistent memory deficits and consistent neuronal loss in the hippocampus and cerebral cortex (Ferreira et al., 2011; Godinho et al., 2015). It also leads to white matter pathology, characterized by the rarefaction and vacuolization of myelinated fibers, oligodendrocyte death, and microglial activation (Wakita et al., 2002; Farkas et al., 2004). Both hippocampal neurodegeneration and white matter injury are thought to contribute to the cognitive impairments that are frequently observed in conditions of $\mathrm{CCH}$.

The present study investigated the effects of roflumilast on cognitive impairments, neurodegeneration, and white matter injury that were induced by $\mathrm{CCH}$ in aged rats. Given the presence of PDE4 in inflammatory cells (microglia and astrocytes) in the brain and the involvement of PDE4 in synaptic plasticity, we also examined the effects of roflumilast on neuroinflammation (i.e., the expression of glial fibrillary acidic protein [GFAP], ionized calcium binding adaptor molecule 1 [Iba1], inducible nitric oxide synthase [iNOS], and arginase-1 [ARG-1]) and markers of neural plasticity (i.e., CREB, phosphorylated CREB [PCREB], brain-derived neurotrophic factor [BDNF], and doublecortin [DCX]) in the hippocampus in aged $\mathrm{CCH}$ rats.

\section{Materials and methods}

\subsection{Animals}

Sixty-nine aged male Wistar rats (500-600 g, 20 months old) were acquired from the local vivarium of the State University of
Maringá (Paraná, Brazil). The animals were housed under controlled temperature $\left(22 \pm 1^{\circ} \mathrm{C}\right)$ on a $12 \mathrm{~h} / 12 \mathrm{~h}$ light/dark cycle. The animals had free access to tap water and a standard commercial chow diet (Nutrilab-CR1; Nuvital Nutrients, Curitiba, PR, Brazil). All experiments were conducted according to the guideline laid out by the Brazilian College of Animal Experimentation (COBEA) and were approved by the Ethics Committee on animal Experimentation of the State University of Maringá (CEUA $\mathrm{n}^{\circ}$ 2675220317).

\subsection{Surgery}

The 4VO/ICA model was used to induce CCH (Neto et al., 2005). The $4 \mathrm{VO} / \mathrm{ICA}$ model consisted in gradually reducing the cerebral blood flow through a permanent occlusion of vertebral arteries (VA) and both internal carotid arteries (ICA) in 3 stages, with an interstage interval of 4 days. First, the animals were anesthetized with a halothane/oxygen mixture and delivery through a universal vaporizer that was regulated by a bubble flow of $0.5 \mathrm{~mL} / \mathrm{min}$ connected to a face mask that was adapted to the rat's nose. The head of the animal was then fixed in a stereotaxic frame for bilateral electrocoagulation of the VA, and a longitudinal incision was made in the dorsal neck at the level of the first cervical vertebra. The tip of a unipolar electrode was inserted into the alar foramen and rotated until the presence of hemorrhage, then immediately stanched by a 3-4 mA electrical current, ensuring complete and irreversible bilateral VA occlusion (VAo; Day 0). Four days later (Day 4), an incision was made in the ventral neck to expose the left ICA, which was carefully dissected and permanently ligated using cotton thread. This procedure was repeated on Day 8 for occlusion of the right ICA. During surgery, core temperature was maintained around $37.5^{\circ} \mathrm{C}$ by a heating blanket. During the first 2 to $3 \mathrm{~h}$ after each surgery stage, the rats were maintained in a warming box (inner temperature, $30 \pm 1^{\circ} \mathrm{C}$ ) to avoid eventual brain hypothermia (Seif el Nasr et al., 1992). Animals assigned to the sham-operated groups were subjected to the same surgical procedures as their counterparts but did not receive vessel occlusions.

\subsection{Drugs}

Roflumilast (a gift from Dr Jos Prickaerts, Maastricht University, The Netherlands) was dissolved in 98\% carboximethylcellulose solution ( $0.5 \%$ carboximethylcellulose) and $2 \%$ Tween 80 and administered intraperitonally (i.p) once a day, for 29 days. The doses of roflumilast $(0.003 \mathrm{mg} / \mathrm{kg}$ and $0.01 \mathrm{mg} / \mathrm{kg})$ were chosen because they were the most effective doses in recovering the memory deficits induced by the muscarinic acetylcholine receptor antagonist scopolamine in rats (Vanmierlo et al., 2016).

\subsection{Experimental design}

Naive rats were trained for 15 days to learn the task in an 8-arms aversive radial maze (AvRM) and then assigned to different treatment groups. Three-stage 4VO/ICA surgery, with an interstage interval of 4 days was performed on days 0,4 , and 8 . After full recovery from anesthesia, drug treatments began after the first occlusion stage and continued during 29 days. Retrograde memory performance was assessed in retention memory trials (RMTs), which began 1 week after the last stage of $4 \mathrm{VO} / \mathrm{ICA}$ surgery and continued for next 3 weeks at a rate of 1 RMT/week (on days 15, 22, and 29). On the day after the last RMT, animals were sacrificed and had their brains removed for histological and biochemical analyses (see Fig. 1 for a general timeline). 


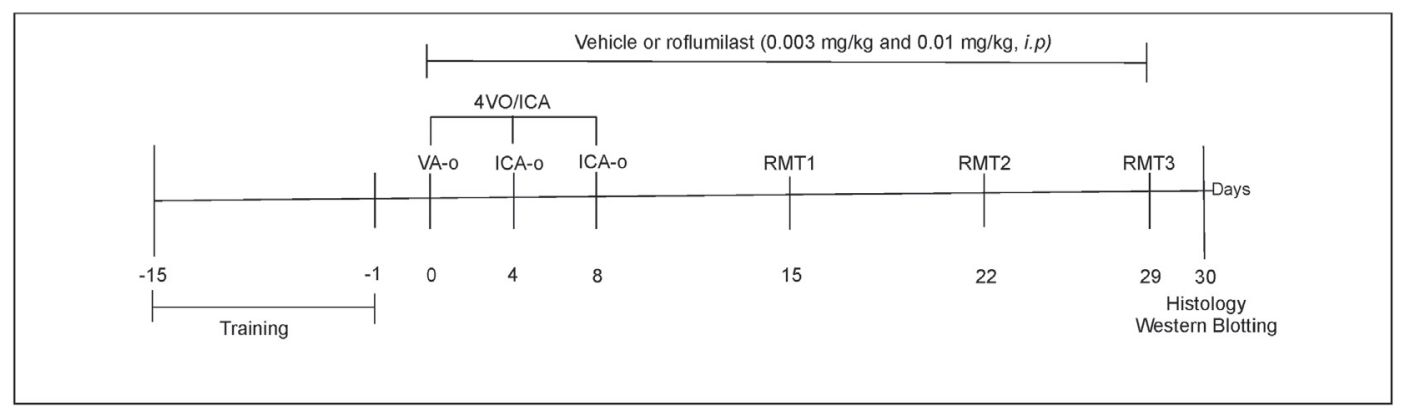

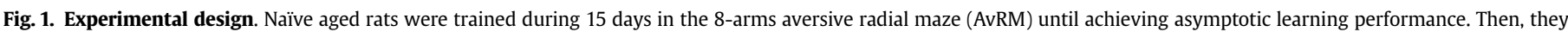

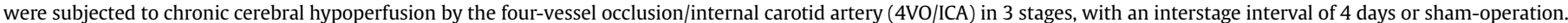

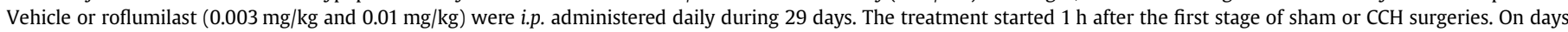

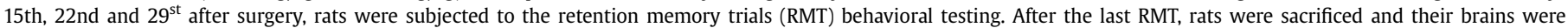
processed for histology and western blot analysis. VA-o, vertebral artery occlusion; ICA-o, internal carotid artery occlusion.

\subsection{Behavioral testing}

The 8-arm aversive radial maze.

The AvRM was originally concepted by Paganelli et al. (2004), and subsequently modified (Benetoli et al., 2007). It consists in a central polygonal platform radiating 8 arms. At the end of each arm an opening provided access to a dark wooden box. Only one contained the true refuge (a close-ended box, the goal box) that could be shifted from one arm to another between trials. In the remaining arms, the boxes were open-ended, i.e, they had walls like the true box (the goal box), however, lack the bottom. At first, naive animals were habituated to AvRM for one day and then trained for 15 days. The acquisition trial began when the rats were placed individually in the center of the maze, after $30 \mathrm{~s}$ the guillotine doors were then opened simultaneously, and the animal was allowed to explore the entire maze. When the animal entered in a non-rewarded arm (i.e., containing a false goal-box) the guillotine doors of the remaining arms were lowered simultaneously. Upon the rats return to central area, the newly visited arm was closed immediately, and the animal was again confined in the arena for further $10 \mathrm{~s}$. The trial ended when the animal found the goal box or the 4 min period elapsed. If the goal box was not found within $4 \mathrm{~min}$, the rat was placed into the arm containing the correct goal box and gently forced to enter it by the experimenter. The rat remained in the goal box for $1 \mathrm{~min}$, after which it was returned to its home cage.

Each acquisition consisted in 3 trials and at the end of the trials the maze was cleaned and randomly rotated on its central axis. The goal box was randomly moved to any of the other seven arms, although its spatial position in relation to the extra maze cues was kept constant across trials and sessions and was the same for all rats. Behavioral performance was measured by the latency to find the goal box, the number of reference memory errors, and the number of working memory errors. Within a given trial, a reference memory error was counted when the rat visited an arm containing a false goal box for the first time. However, if the rat returned to an arm that had been visited previously during that trial, then a working memory error was recorded.

On the last day of training, four experimental groups were randomly generated: Sham + vehicle (Sham + veh, $\mathrm{n}=30$ ), $\mathrm{CCH}+$ vehicle $(\mathrm{CCH}+$ veh, $\mathrm{n}=10), \mathrm{CCH}+$ roflumilast $0.003 \mathrm{mg} / \mathrm{kg}$ $(\mathrm{CCH}+\mathrm{ROF} 0.003, \mathrm{n}=10)$ and $\mathrm{CCH}+$ roflumilast $0.01 \mathrm{mg} / \mathrm{kg}$ $(\mathrm{CCH}+\mathrm{ROF} 0.01, \mathrm{n}=11)$. Group assignment was balanced based on individual acquisition performance calculated as the mean latency observed across the last 3 days of preoperative training (days -3 to -1 ). Seven days after the third occlusion stage, cognitive tests of memory retention, i.e., retrograde memory, began. On day 30 , the animals were euthanized and had their brains removed for histological analysis.

\subsection{Histology: cresyl violet and fast blue staining}

Half of the rats were deeply anesthetized with $50 \mathrm{mg} / \mathrm{kg}$ sodiumthiopental (Thiopentax; Cristália, SP, Brazil) and transcardially perfused with $0.9 \%$ saline followed by Bouin's fixative (22 $\mathrm{ml} / \mathrm{min}$ for $7-10 \mathrm{~min}$ ) using a peristaltic pump. Following decapitation, the head was immersed in crushed ice $(1-2 \mathrm{C})$ for $2 \mathrm{~h}$. The brain was carefully removed, the cerebellum was discarded, and the hemispheres were sectioned coronally at the level of the optic chiasm into two blocks that were post fixed in Bouin's solution for 3 to 5 days. The blocks were dehydrated, cleaned, and embedded paraffin according to standard procedures. A rotating microtome (LEICA RM2445, Wetzlar, Germany) was used to cut $7 \mu \mathrm{m}$ coronal slices at a stereotaxic hippocampus level between -3.6 and $-4.3 \mathrm{~mm}$ posterior to bregma.

For cresyl violet staining (Nissl), the brain slices were hydrated by immersion ( $5 \mathrm{~min}$ ) in serial, decreasing alcohol concentrations (100\%, 95\%, 70\%) in distilled water and then incubated in $0.3 \%$ cresyl violet solution for 5-7 min. Excessive stain was removed by briefly immersing the slides in a $95 \%$ alcohol solution, followed by dehydration in absolute alcohol. The tissue was cleared in xylene for 5 min and cover slipped with Permount ${ }^{\circledR}$. Images from the hippocampus were obtained with the aid of a binocular microscope (400x magnification, Olympus BX41, Tokyo, Japan) coupled to a color, high-performance device camera (QColor, Ontario, Canada). Cells presenting a well-delimited, spherical form with a distinct nucleus and nucleolus were considered viable. Those that had shrunken cell bodies or surrounding empty spaces were considered destined to die and excluded from counting. The number of preserved cells was quantified in the CA1, CA2, CA3 and CA4 hippocampal subfields. For each animal, the measurements were taken in both cerebral hemispheres, summed and normalized to the mean of the Sham + veh group, which was considered $100 \%$. Normalized values were used to represent the percentage of normal-looking pyramidal neurons in each group.

In an adjacent set of slides, luxol fast blue die (Kluver Barrera's staining) was used for semi quantitative assessment of white matter. After standand deparafinization and hydratation, the slides were immersed in luxol fast blue $0.1 \%$ overnight. Then the slides were rinsed in ethanol $70 \%$ and water to remove the excess of luxol fast blue. Lithium carbonate $0.05 \%$ was used to differentiate white matter. The slides were dehydratated with $95 \%$ and $100 \%$ alcohol followed by xylene during $5 \mathrm{~min}$. The slides were mounted in gelatin coated slides using Permount and coverslips. After recorded, the images were evaluated by measuring the integrated optical density (IOD) using 
Image s software (National Institutes of Health, Bethesda, MD, USA). To evaluate the IOD the images was converted to gray scale, the background subtracted and the integrated optical density (IOD) obtained. The IOD measurements were determined in prefixed areas located in corpus callosum $\left(0.27 \mathrm{~mm}^{2}\right)$ and optic tract $\left(0.16 \mathrm{~mm}^{2}\right)$. Results were presented as the mean \pm S.E.M. of three sections/animal.

\subsection{Western blot analysis}

Another half of the animals were decapitated, their brains carefully removed and the whole hippocampus isolated by microdissection and snap-frozen in liquid nitrogen. The tissue samples were lysed with lysis buffer $(50 \mathrm{mM}$ Tris, $600 \mathrm{mM} \mathrm{NaCl}, 1 \mathrm{mM}$ EDTA) containing protease and phosphatase inhibitors (SigmaAldrich, St. Louis, MO, USA) and centrifuged for $20 \mathrm{~min}$ at $4{ }^{\circ} \mathrm{C}$ at $12000 \mathrm{rpm}$. The supernatant was assayed for total protein concentrations using the Bio-Rad Lowry Protein Assay (Bio-Rad Laboratories Inc., Hercules, USA).

Hippocampal homogenates (30 $\mathrm{g}$ protein each) in sample buffer were separated on a 15\% (Iba 1 and BDNF), 12\% (GFAP, ARG-1, pCREB, CREB and DCX) or 8\% (iNOS) SDS-PAGE gel, using a total of eight different blots to measure all different proteins. After protein transfer into a nitrocellulose membrane (Bio-Rad Laboratories, Hercules, USA), membranes were blocked (2\% BSA in TBS buffer) and incubated with the primary antibody at $4{ }^{\circ} \mathrm{C}$ overnight at the following dilutions: rabbit anti-GFAP (1:2000; Abcam, Cambridge, MA, USA), rabbit anti-IBA1 (1:1000; Wako Chemicals, Richmond, VA, USA), rabbit anti-iNOS (1:1000; Sigma-Aldricht, Saint Louis, MO, USA), mouse anti-ARG-1 (1:800; Santa Cruz Biotechnology, Santa Cruz, CA, USA), rabbit anti-pCREB (1:100; Cell Signaling, Danvers, MA,USA), mouse anti-CREB (1:500; Cell Signaling, Danvers, MA,USA), rabbit anti-BDNF (1:400; Santa Cruz Biotechnology, Santa Cruz, CA, USA), rabbit anti-DCX (1:500; Abcam, Cambridge, MA, USA) and mouse anti-GAPDH (1:5000; Santa Cruz Biotechnology, Santa Cruz, CA, USA). After a washing step with TBS, membranes were incubated for $2 \mathrm{~h}$ with horse radish peroxidaseconjugated donkey anti-rabbit IgG (1:2500 Abcam, Cambridge, MA, USA) or donkey anti-mouse IgG (1:2000; Abcam, Cambridge, MA, USA) and were finally developed using ECLplus ${ }^{\circledR}$ (Invitrogen, Carlsbad, CA, USA). In order to assess the protein control (GAPDH) all blots were stripped with harsh stripping buffer (20\% SDS $10 \%$, $12.5 \%$ Tris $\mathrm{HCl} 0.5 \mathrm{M}$ and $0.8 \%$ ß-mercaptoethanol in $\mathrm{H}_{2} \mathrm{O}$ ). Bands were visualized using ChemiDoc Imaging Systems (Bio-Rad, Hercules, CA, USA). Intensities of specific bands were quantified using Image (NIH, Bethesda, MD, USA) and normalized to GAPDH protein levels. Data were presented as \% of the Sham + veh group (control).

\subsection{Primary microglia isolation}

Primary mixed glial cultures were isolated and cultured as described previously (O'Meara et al., 2011). In brief, mixed glial cultures were prepared from postnatal do cerebral cortices of Wistar rats (Envigo, Venlo Netherlands B.V) and cultured in high glucose DMEM medium supplemented with $10 \%$ FCS and $100 \mathrm{U}$ pen/ $100 \mu \mathrm{g}$ strep $/ \mathrm{ml}$. Mixed glial cultures were used to generate microglia-enriched glial cultures by separating the microglia from the astrocyte monolayer by orbital shaking followed by purification by differential adhesion to plastic after 14 days in culture. Purified microglia were seeded on poly-L-lysine $(5 \mu \mathrm{g} / \mathrm{ml}$; Sigma-Aldrich) coated 24-well plate at a density of 250.000 cells/well. Primary microglia were treated with $10 \mu \mathrm{M}$ roflumilast or vehicle $11: 1000$ DMSO) in high glucose DMEM medium supplemented with $10 \%$ FCS, 100U pen $/ 100 \mu \mathrm{g}$ strep $/ \mathrm{ml}$ and $15 \%$ L929 conditioned medium for $24 \mathrm{~h}$ in presence or absence of myelin $(100 \mu \mathrm{g} / \mathrm{ml}$; kindly provide by Dr. J.F.J. Bogie, Hasselt University, Hasselt, Belgium).
Subsequently, microglia were treated with a combination of interleukin $1 \beta$ (IL-1 $\beta, 101 \mathrm{ng} / \mathrm{ml}$; PeproTech, London, United Kingdom) and interferon $\gamma$ (IFN- $\gamma, 100 \mathrm{ng} / \mathrm{ml}$; PeproTech, London, United Kingdom) $6 \mathrm{~h}$ preceding lysis for qPCR.

\subsection{RNA isolation and $R T-q P C R$}

Primary rat microglia were lysed in Qiazol (Qiagen, Venlo, The Netherlands) preceding RNA isolation, and total RNA was prepared using the RNeasy mini kit (Qiagen, Hilden, Germany), according to manufacturer's instructions. RNA concentration and quality was determined with a NanoDrop spectrophotometer (Isogen Life Science, IJsselstein, The Netherlands). RNA was reverse transcribed to cDNA using the qScriptTM cDNA synthesis kit (Quanta Biosciences, Gaithersburg, USA). Quantitative PCR was subsequently conducted on a StepOnePlus detection system (Applied biosystems, Gaasbeek, Belgium). Relative quantification of gene expression was performed using the comparative $\mathrm{Ct}$ method. Data were normalized to the most stable reference genes. Primers were chosen according to literature or designed using Primer-Express (http://www.ncbi.nlm.nih.gov/ tools/primer-blast), and details of primers used are shown in Table 1.

\subsection{Statistical analysis}

SAS 9.3 software was used for the analysis, which followed as described previously (Godinho et al., 2015). Briefly, the behavioral and histological data were examined for assumptions of normality and homocedasticity. Since behavioral data did not follow normal distribution (D'Agostino and Pearson omnibus test) and homoscedasticity (Levene's test), we firstly determined the covariance model to which the row data fit better. To this end, the following information criteria were used: (i) Akaike's information criterion (AIC), (ii) Akaike's information criterion corrected (AICC), (iii) Bayesian information criterion (BIC), and (iv) the Likelihood ratio test. The autoregressive (AR) covariance structure was then used. A two-way analysis of variance (ANOVA) for repeated-measures was performed to quantify memory performance across the various days of testing, with Group as the between-subjects factor and Trial (testing day) as the within-subjects factor. When memory performance was expressed by the parameters 'total latency' and 'total number of errors', the one-way ANOVA was used for betweengroup comparisons. If a main effect of Group was found for the behavioral data, Tukey-Kramer's multiple range test was used to distinguish between groups. Paired Student's t-test was applied for within-group comparisons of memory performance measured prior to and after ischemia. Once the histological data also did not follow a normal distribution and homoscedasticity, the generalized linear model with a Poisson distribution was used for the count data (i.e., the number of Nissl-stained cells) and the generalized linear model with a gamma distribution was used for continuous data (i.e., the IOD for Kluver Barrera-stained cells and Western blot data). To evaluate survival data a proportion-like $t$-test was used. Primary rat microglia data were analyzed using two-way ANOVA (roflumilast $x$ IFN- $\gamma /$ IL-1 $\beta$ ). Values of $p<0.05$ were considered statistically significant. Extreme values were excluded by means of Dixon's principles of exclusion of extreme values (Dixon, 1959).

Table 1

Rat primers for RT-qPCR.

\begin{tabular}{lll}
\hline Gene & Forward & Reverse \\
\hline ACTB & TGTCACCAACTGGGACGATA & GGGGTGTTGAAGGTCTCAAA \\
PGK1 & ATGCAAAGACTGGCCAAGCTAC & AGCCACAGCCTCAGCATATTTC \\
Arg-1 & CAAGCTGGGAATTGGCAAAG & GGTCCAGTCCATCAACATCAAA \\
\hline
\end{tabular}




\section{Results}

\subsection{Survival rate}

Overall, 69 animals entered the experiment. No death was observed in the Sham + veh group (0/30, 100\% survival rate). In comparison to Sham + veh group, however, a significant effect of $\mathrm{CCH}$ was detected, as seen by 6 deaths in 16 animals $(6 / 16,62.5 \%$ survival rate, $p<0.01)$. Roflumilast $0.01 \mathrm{mg} / \mathrm{kg}(0 / 11,100 \%$ survival rate) but not roflumilast $0.003 \mathrm{mg} / \mathrm{kg}(2 / 12,83.3 \%$ survival rate) reduced the mortality in aged rats subjected to $\mathrm{CCH}(p=0.1)$.

\subsection{Roflumilast prevents memory impairment in $\mathrm{CCH}$ aged rats}

Fig. 2 shows the effect of roflumilast (ROF) on retrograde memory performance in aged rats that were subjected to $\mathrm{CCH}$ and evaluated in the AvRM test. An increase in latency, number of reference memory errors, and number of working memory errors indicates that the rats forgot the spatial location of the goal box that was learned during preoperative training. The longitudinal analysis of data (Fig. 2b,c,2d) revealed a highly significant main effect of Group for all the three parameters $\left(F_{3,171}=7.72\right.$ to $\left.17.39, p<0.001\right)$. Although a global effect of Trial was not detected by ANOVA for any of the three parameters $\left(F_{2,171}=0.63\right.$ to $\left.3.13, p>0.05\right)$, the number of errors appeared to increase over time, a more consistent effect for the parameter 'reference memory errors'. This finding suggests a progressive deterioration of memory. The post hoc analysis revealed that both latency and number of errors were significantly elevated in the $\mathrm{CCH}+$ veh group $(p<0.0001)$, indicating a state of retrograde amnesia in that group. $\mathrm{CCH}$-induced loss of retrograde memory is also evident by the parameters total latency and total number of errors that were summed over the RMTs (Fig. 2e, f, 2g; $\mathrm{F}_{3,60}=10.69$ to $17.07, p<0.0001$ to $0.001, \mathrm{CCH}+$ veh in comparison to Sham + veh group). This memory deterioration following $\mathrm{CCH}$ was further confirmed by a within-group analysis that compared the total latency and total number of errors that were measured prior to and after $\mathrm{CCH}$. This analysis revealed that all three parameters consistently increased from preoperative training to postoperative RMTs in the $\mathrm{CCH}+$ veh groups $(\mathrm{t}=-6.05$ to -4.22 , $p<0.0001$ to 0.01 ). This did not occur, however, in Sham + veh rats ( $\mathrm{t}=-1.53$ to $-0.45, p>0.05$ ). Collectively, these results indicate that $\mathrm{CCH}$ caused the rats to forget the task that they learned prior to $\mathrm{CCH}$ (i.e., retrograde amnesia), an effect from which they did not spontaneously recover during the experiment. This memory deficit caused by $\mathrm{CCH}$ and reflected by all three parameters and analyses, was significantly alleviated by roflumilast, independently of the doses used (Fig. 2b, c, 2d; $p<0.0001$ to 0.05 , and Fig. 2e, f, 2g; $p<0.0001$ to $0.01, \mathrm{CCH}+\mathrm{ROF}(0.003 \mathrm{mg} / \mathrm{kg}$ and $0.01 \mathrm{mg} / \mathrm{kg})$ in comparison to $\mathrm{CCH}+$ veh; Fig. $2 \mathrm{e}, \mathrm{f}, 2 \mathrm{~g} ; p=0.10$ to $0.70, \mathrm{CCH}+\mathrm{ROF}$ $(0.003 \mathrm{mg} / \mathrm{kg}$ and $0.01 \mathrm{mg} / \mathrm{kg}$ ) preoperative $v s . \mathrm{CCH}+\mathrm{ROF}$ (0.003 $\mathrm{mg} / \mathrm{kg}$ and $0.01 \mathrm{mg} / \mathrm{kg}$ ) postoperative).

\subsection{Roflumilast fails to restrain hippocampal neurodegeneration while protects white matter from ischemic injury in $\mathrm{CCH}$ aged rats}

The results of the histological analysis are illustrated in Fig. 3. $\mathrm{CCH}$ caused significant reduction in the number of intact appearing neurons in the hippocampus, evidenced by neurons that had

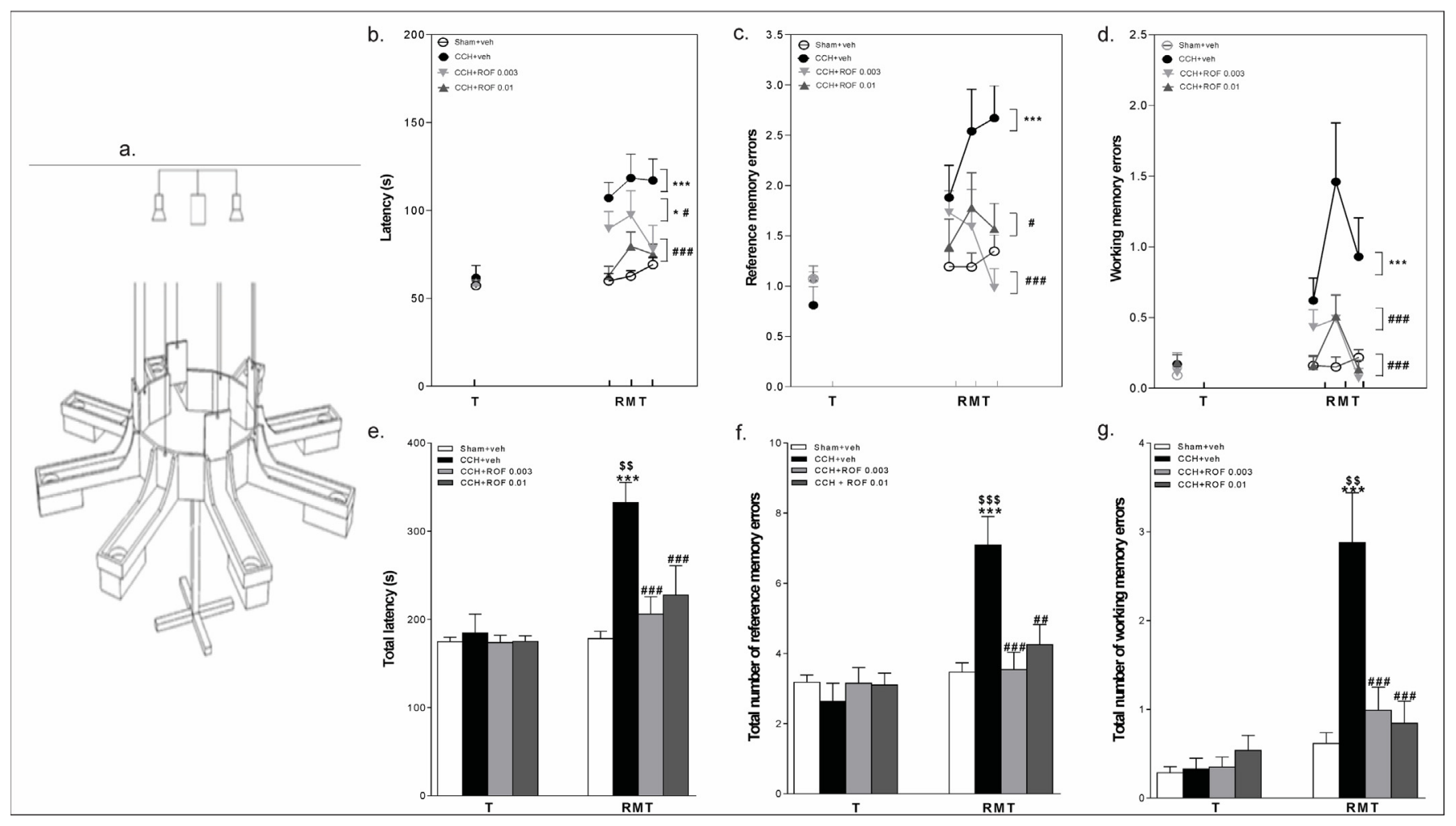

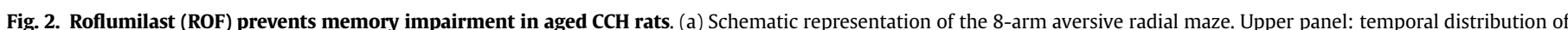

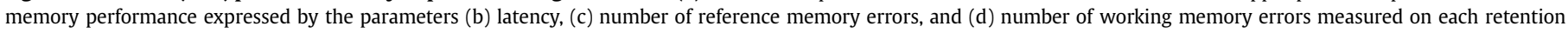

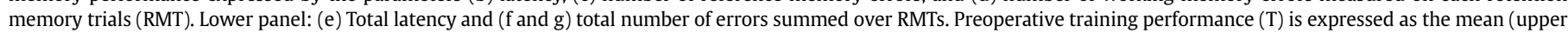

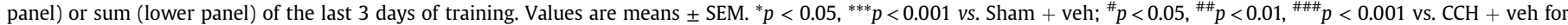

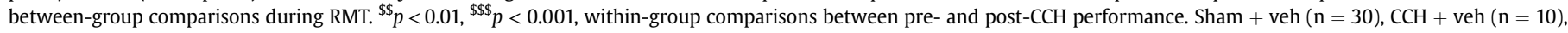
$\mathrm{CCH}+\operatorname{ROF} 0.003(\mathrm{n}=10), \mathrm{CCH}+\mathrm{ROF} 0.01(\mathrm{n}=11)$. 
shrunken cell bodies or surrounding empty spaces which were considered to have died in the Nissl staining (Fig. 3b; $\chi^{2}=184.5$, $p<0.0001 ; \mathrm{CCH}+$ veh $v$. Sham + veh, $p<0.0001)$. This neurodegenerative effect of $\mathrm{CCH}$ was not counteracted by roflumilast, independently of the doses used $[p>0.05, \mathrm{CCH}+\mathrm{ROF}(0.003 \mathrm{mg} / \mathrm{kg}$ and $0.01 \mathrm{mg} / \mathrm{kg}$ ) vs. $\mathrm{CCH}+$ veh].

Regarding the results of Kluver-Barrera staning, no significant difference between groups considering rarefaction or fiber disarrangement of white matter in the corpus callosum (Fig. 3c; $\left.\chi^{2}=3.03, p=0.38\right)$. Differences were found, however, in the optic tract (Fig. 3d; $\chi^{2}=20.01, p=0.0002$ ). Overall, $\mathrm{CCH}+$ veh group exhibited more vacuolization and fiber disarrangement, reflected by a significant decrease in the IOD when compared with Sham + veh group $(p<0.0001)$. Otherwise, repeated roflumilast treatment $(0.003 \mathrm{mg} / \mathrm{kg}$ and $0.01 \mathrm{mg} / \mathrm{kg})$ prevented the white matter injury in the optic tract when compared to $\mathrm{CCH}+$ veh group $(\mathrm{CCH}+$ ROF 0.003, $p=0.002 ; \mathrm{CCH}+\mathrm{ROF} 0.01$, $p<0.0001)$.

a.

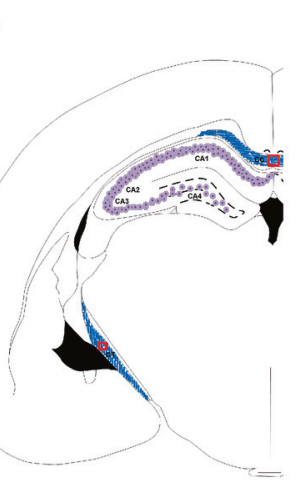

b.

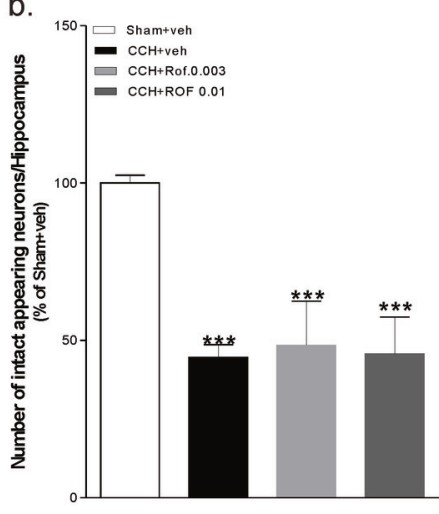

3.4. Roflumilast changes inflammatory response in the hippocampus of $\mathrm{CCH}$ aged rats

Western blot analysis revealed differences in the protein levels of GFAP $\left(\chi^{2}=17.13, p=0.0007\right)$, Iba-1 $\left(\chi^{2}=10.65, p=0.01\right)$, ARG-1 $\left(\chi^{2}=9.06, p=0.02\right)$ but not iNOS $\left(\chi^{2}=5.54, p=0.13\right)$ in the hippocampus of aged rats (Fig. 4). Treatment with roflumilast $0.01 \mathrm{mg} /$ $\mathrm{kg}$ induced an increase in the levels of GFAP $(p=0.0004)$, Iba-1 $(p=0.008)$ and ARG-1 $(p=0.01)$ in aged CCH rats as compared to $\mathrm{CCH}+$ veh group (see Fig. 5).

\subsection{Roflumilast induces expression of Arg-1 in myelin-laden microglia}

Overall, the two-way ANOVA showed no effect of treatment $\left(F_{1,53}=1.92 ; p>0.05\right)$. However, a significant effect appeared for the experimental conditions "IFN- $\gamma / \mathrm{IL}-1 \beta$ and myelin" $\left(\mathrm{F}_{3,53}=5.80\right.$; $p<0.001)$. A significant interaction between treatment and
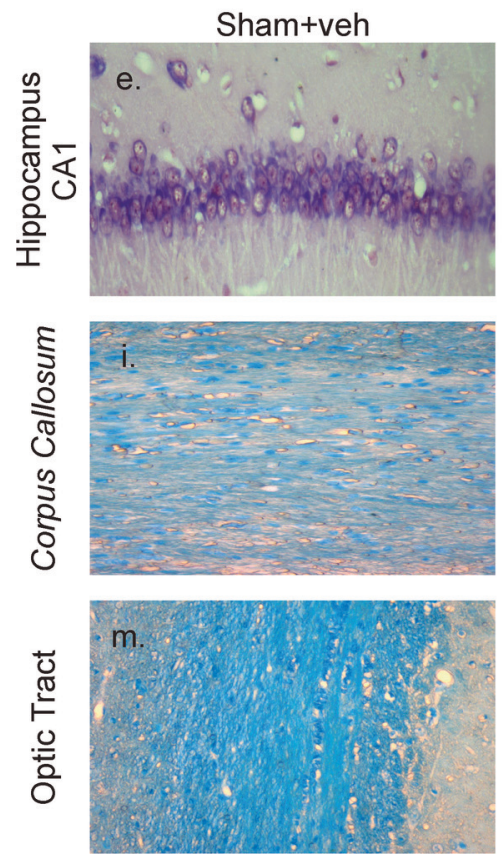
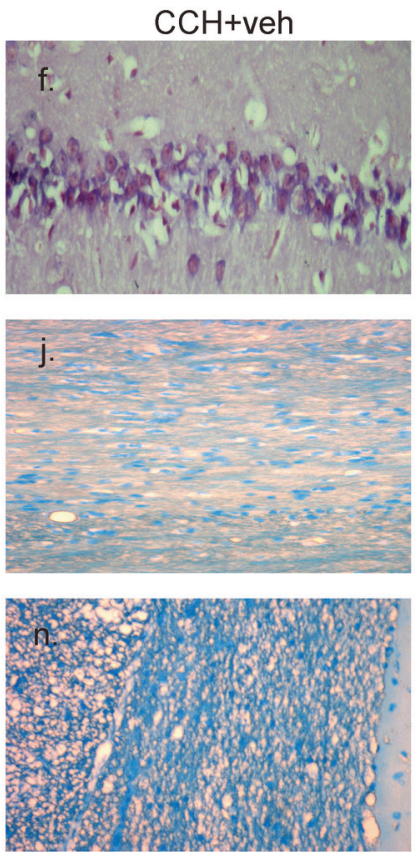
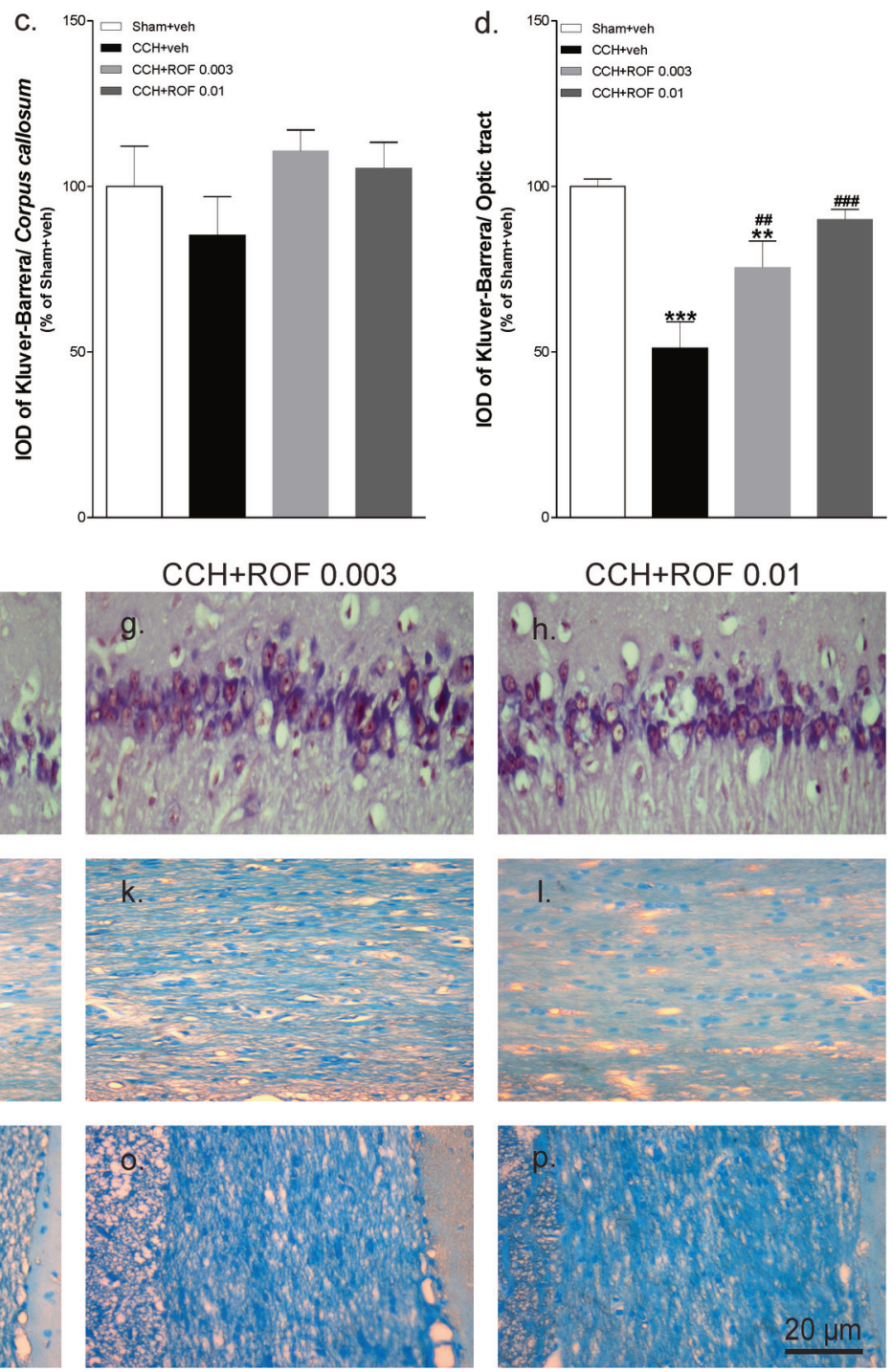
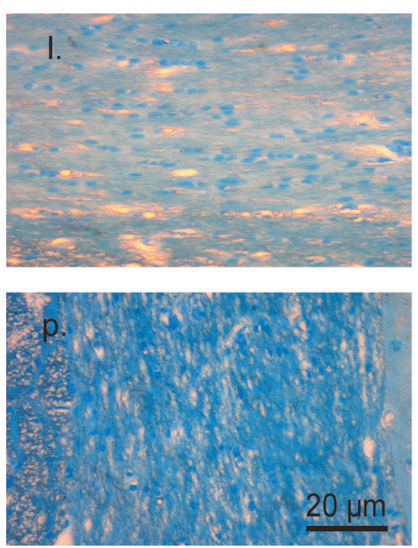

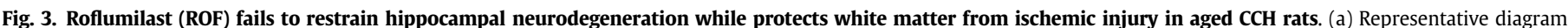

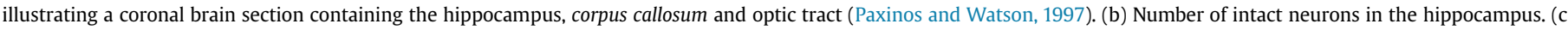

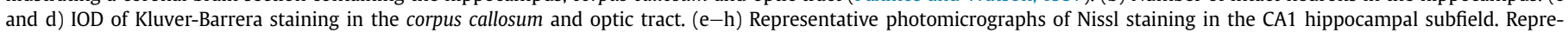

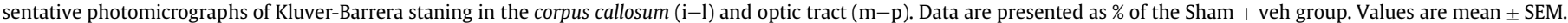

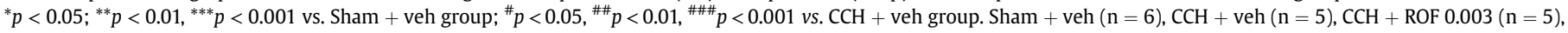
$\mathrm{CCH}+\mathrm{ROF} 0.01(\mathrm{n}=5)$. 

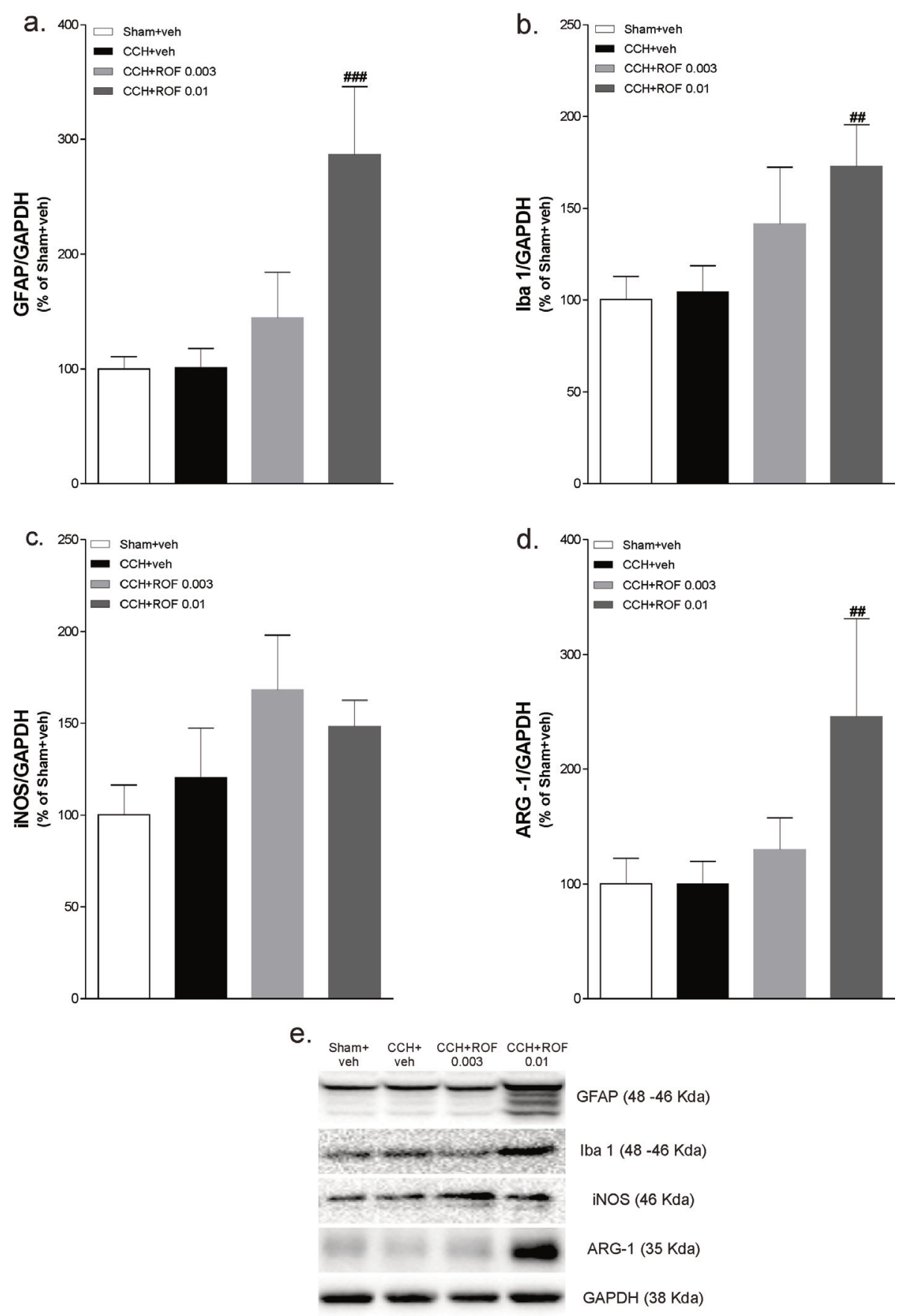

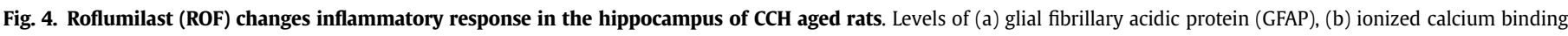

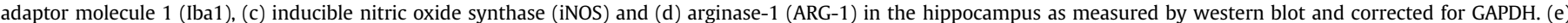

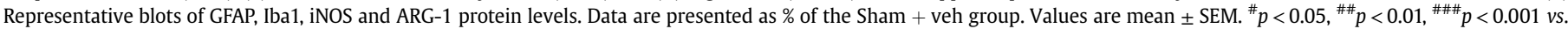
$\mathrm{CCH}+$ veh group. Sham + veh $(\mathrm{n}=6), \mathrm{CCH}+$ veh $(\mathrm{n}=5), \mathrm{CCH}+\mathrm{ROF} 0.003(\mathrm{n}=5), \mathrm{CCH}+\mathrm{ROF} 0.01(\mathrm{n}=6)$.

conditions was also detected $\left(\mathrm{F}_{3,53}=3.18 ; p<0.05\right)$. Sidak's multiple range test indicated that roflumilast increased $\mathrm{Arg}-1$ gene expression under the "myelin-laden and Inf- $\gamma / \mathrm{IL}-1 \beta$ " condition in primary microglia $(p<0.05)$.

\subsection{Roflumilast does not affect expression of neuronal plasticity markers in the hippocampus of $\mathrm{CCH}$ aged rats}

As shown in Fig. 6, no significant differences was detected in the protein levels of pCREB/CREB $\left(\chi^{2}=1.48, p=0.68\right)$, BDNF $\left(\chi^{2}=1.10\right.$, $p=0.77)$ or $\mathrm{DCX}\left(\chi^{2}=0.64, p=0.88\right)$ in the hippocampus of $\mathrm{CCH}$ aged rats (Fig. 6). Neither $\mathrm{CCH}$ nor $\mathrm{CCH}+$ roflumilast $(0.003 \mathrm{mg} / \mathrm{kg}$ and $0.01 \mathrm{mg} / \mathrm{kg}$ ) were able to alter the hippocampal expression of these plasticity markers in $\mathrm{CCH}$ aged rats.

\section{Discussion}

Aging and $\mathrm{CCH}$ are important risk factors and contributors to vascular dementia, including Alzheimer's disease (De La Torre, 2009). The present study found that the selective PDE4-I 


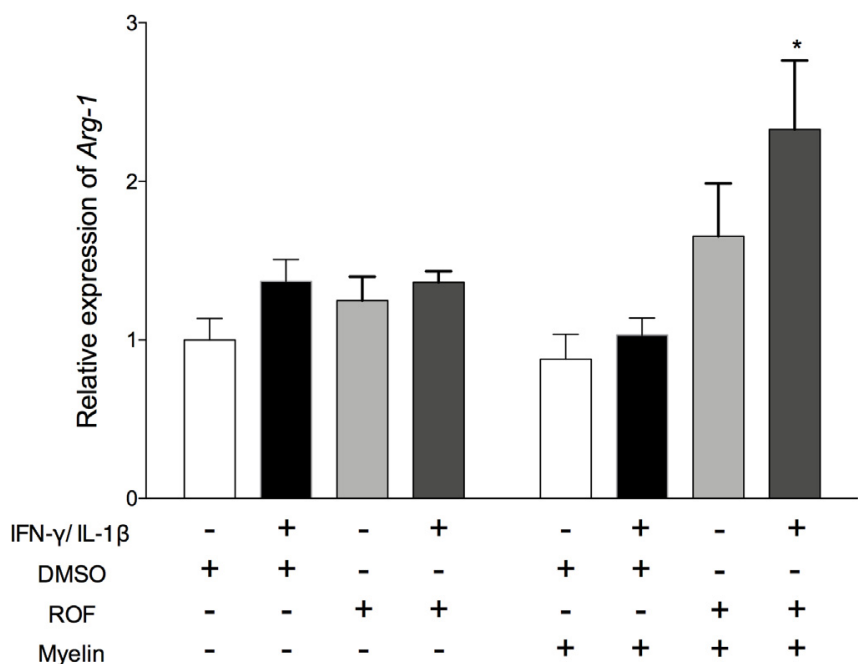

Fig. 5. Roflumilast (ROF) suppresses induces expression of $\operatorname{Arg} 1$ in primary microglia in presence of myelin debris. Primary rat microglia were cultured and stimulated with or without IFN- $\gamma / \mathrm{IL}-1 \beta$ to determine the influence of ROF $(10 \mu \mathrm{M})$ or vehicle (DMSO) on the relative mRNA expression of Arg-1. The expression was determined in the absence or presence of myelin debris $(100 \mu \mathrm{g} / \mathrm{ml})$. qPCR data were accomplished using comparative $C t$ method. Data were normalized to the most stable reference genes, determined by Genorm ( $T b p$ and $C y c a)$. Values are mean \pm SEM ( $\mathrm{n}=7-8$ per group). ${ }^{*} p<0.05 v s$. IFN- $\gamma /$ IL- $1 \beta+$ myelin group.

roflumilast increased survival rates and improved cognitive performance in aged rats that were subjected to $\mathrm{CCH}$. Roflumilast also attenuated $\mathrm{CCH}$-induced white matter injury in the optic tract in aged rats and changed inflammatory signaling in the CNS resident cells. To our knowledge, this is the first study that evaluated the effects of roflumilast under conditions of $\mathrm{CCH}$ and white matter pathology. The present findings support the use of roflumilast as a therapeutic strategy for the treatment or prevention of cognitive disorders associated with $\mathrm{CCH}$.

Persistent memory deficits are consistently observed following the 4VO/ICA model of $\mathrm{CCH}$ in aged rats (Pereira et al., 2011; Romanini et al., 2013; Ferreira et al., 2013; Godinho et al., 2015; Nunes Santiago et al., 2018). Accordingly, we found that aged $\mathrm{CCH}$ rats performed worse in the AvRM than control sham animals. These findings demonstrate that long-term memory that was acquired before $4 \mathrm{VO} / \mathrm{ICA}$ did not spontaneously recover, indicating a condition of persistent retrograde amnesia. Moreover, the cognitive deficits that were induced by $\mathrm{CCH}$ in aged rats may be interpreted as a correlate of functional cognitive impairments that are observed in aged humans with cerebrovascular deficiency (Luckhaus et al., 2008).

Repeated treatment with roflumilast $(0.003$ and $0.01 \mathrm{mg} / \mathrm{kg}$ ) attenuated $\mathrm{CCH}$-induced cognitive impairments in aged rats in the hippocampus-dependent task evaluated in the AvRM. In contrast, aged sham-operated animals that received roflumilast did not differ from each other whatever the parameters examined in the AvRM (data not shown). Our results are consistent with previous studies that reported that the prototypical PDE4-I rolipram improved learning and memory function under several ischemic conditions (Imanishi et al., 1997; Nagakura et al., 2002; Li et al., 2011; Soares et al., 2016). The pro-cognitive effects of rolipram were attributable to the activation of CREB through the PKA/CREB signaling pathway. Jabaris et al. (2015a) showed that the PDE4-I
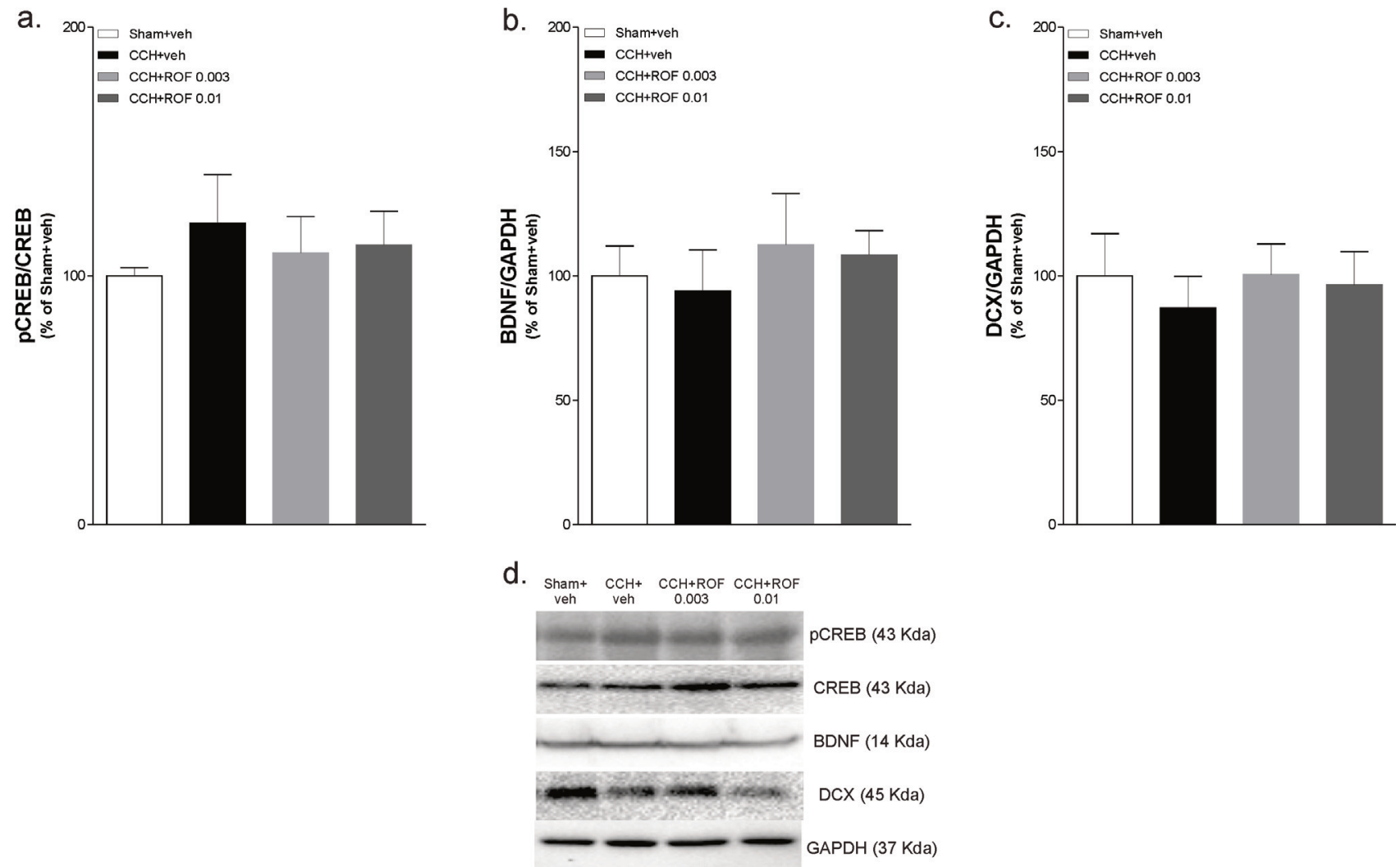

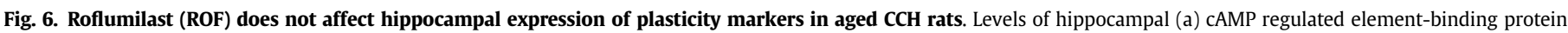

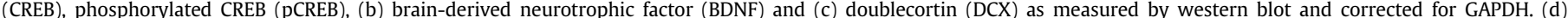

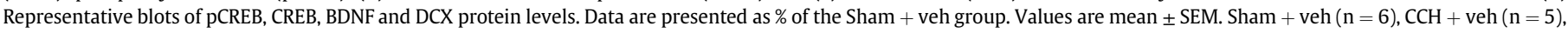
$\mathrm{CCH}+\mathrm{ROF} 0.003(\mathrm{n}=5), \mathrm{CCH}+\mathrm{ROF} 0.01(\mathrm{n}=6)$. 
rolipram and its congener roflumilast ameliorated hypertensioninduced learning deficits via CAMP/CREB signaling in the hippocampus. Indeed, the regulation of cAMP levels in the hippocampus by PDE4 is critically involved in mechanisms of memory formation, such as long-term potentiation (Ricciarelli and Fedele, 2015). Therefore, roflumilast might improve cognitive performance in aged $\mathrm{CCH}$ rats by elevating cAMP and its downstream effectors. However, roflumilast did not affect the levels of the neuroplasticity markers pCREB, BDNF or DCX in the hippocampus of aged CCH rats. These findings contrast with others showing that the PDE4-I rolipram increased the expression of doublecortin (DCX) and microtubule-associated protein (MAP-2) in the hippocampus of young adult ischemic mice (Sasaki et al., 2007; Soares et al., 2016). The discrepancy between those studies and the present one, regarding the effects of PDE4-I (rolipram and roflumilast) on neuroplasticity markers, may reflect the pronounced hippocampal vulnerability to the negative effects of aging (Burke and Barnes, 2006; Shetty et al., 2011; Calabrese et al., 2013). In conditions of acute global brain ischemia, Choi et al. (2012) have shown lower extent of cell proliferation, neuroblast differentiation and neuronal maturation in the hippocampus of aged gerbil in comparison to ischemic adult animals. Although our data showed no effect of $\mathrm{CCH}$ on the protein leves of pCREB, BDNF or DCX (Fig. 6), additional investigations are needed to better understand the impact of $\mathrm{CCH}$ on neuroplasticity markers in aged rats.

There are indications that brain inflammation is driven by different microglial phenotypes, i.e., M1 and M2, and/or by the balance between pro- and anti-inflammatory cytokines produced by activated microglia. While M1 microglia as a pro-inflammatory subtype, has been associated with tissue damage, M2 microglia as an anti-inflammatory subtype, has been shown to facilitate repair and regeneration (Cherry et al., 2014; Loane and Kumar, 2016). Moreover, microglia phenotype may shift form one phenotype to another dependent on microenvironment, time and brain area assessed after an insult (Harry et al., 2013). With aging, however, microglia may display diminished ability to shift from a proinflammatory to an anti-inflammatory state to regulate injury and repair (Koellhoffer et al., 2017). We detected an increase in the levels of GFAP, Iba- 1 and ARG-1 in the hippocampus of aged $\mathrm{CCH}$ rats. Although the present results did not show a clear polarization towards M1 and M2 phenotypes, it is remarkable that microglia were activated in response to $\mathrm{CCH}$ in a pro-inflammatory manner as reflected by upregulation of Iba-1 hippocampal levels. These data are in line with others showing that inflammation generated by acute focal brain ischemia and reperfusion favors M1 phenotype expression (Hu et al., 2012). Roflumilast induced an upregulation of ARG-1 hippocampal levels in vivo, which was confirmed by an increased Arg-1 expression in vitro. Arginase-1 is characterized as a modulator of tissue repair and its expression correlated with recovery after CNS injury (Greenhalgh et al., 2016). To date, mice lacking M2 presented worse outcomes after brain ischemia (Xiong et al., 2011). Moreover, in animals models of neuroinflammation, e.g. experimental autoimmune encephalitis and $A B$ hippocampal deposition (Cherry et al., 2014), an impaired ARG-1 expression by microglia has been reported. Since roflumilast showed to upregulate ARG-1, these findings suggest movement towards the repairinducing M2 phenotype on the M1-M2 spectrum. Interestingly, it has been shown that ARG-1 acts downstream from cAMP pathway (Haffner et al., 2008), which is supportive with the effect of the PDE4-I, roflumilast.

Despite its positive effect on memory, roflumilast did not impact $\mathrm{CCH}$-induced hippocampal cell loss in aged $\mathrm{CCH}$ rats. This was somewhat unexpected because the other PDE4-I, rolipram, conferred protection against neuronal damage in the hippocampus that was induced by focal and global cerebral ischemia (Block et al.,
1997; MacDonald et al., 2007; Li et al., 2011; Soares et al., 2016). However, the above mentioned studies with rolipram were conducted in young rodents. Interestingly, other PDE-I, such as the PDE3-I cilostazol (increases cAMP and cGMP) and the PDE5-I sildenafil (increases cGMP), prevented hippocampal and cortical neurodegeneration in aged CCH rats (Ferreira et al., 2013; Godinho et al., 2015). It was argued that neuroprotection following PDE3-I or PDE5-I treatment was a consequence of cerebrovascular dilatation induced by elevated levels of cGMP. However, it not seems to be the case observed with roflumilast in the present study. The procognitive effects of roflumilast in the absence of histological neuroprotection might indicate that the rescue of neurons in the hippocampus was not necessarily required for memory recovery after $\mathrm{CCH}$ in aged rats. Functional recovery may reflect ultrastructural alterations at cellular, synaptic or electrophysiological levels, or even widespread changes that would not be restrict to a given brain structure (Aronowski et al., 1996). de la Tremblaye and Plamondon (2011), for instance, have shown that $10 \mathrm{~min}$ of global brain ischemia in middle-aged rats resulted in a significant neuronal loss in basolateral amygdala, which was related to memory impairments. In addition, a close relationship between the hippocampus and the prefrontal cortex in cognitive process has also been suggested, indicating that both structures process memory in parallel, one serving as a compensatory mechanism for the other (Lee and Kesner, 2003). Finally, we cannot discard the protective effect of roflumilast against white matter injury induced by $\mathrm{CCH}$, which may also have contributed for recovering of cognitive function.

White matter injury is often observed under conditions of aging, hypertension, and cerebrovascular disease and has been associated with cognitive decline and vascular dementia in the elderly population (Boone et al., 1992; Bolandzadeh et al., 2012; Biffi et al., 2016). Chronic cerebral hypoperfusion leads to the rarefaction and/or vacuolization of myelinated fibers, axonal damage, and the activation of inflammatory cells (i.e., microglia and astrocytes) in the white matter in rats (Ihara et al., 2001; Wakita et al., 2002; Cho et al., 2006; Lee et al., 2006; Watanabe et al., 2006; Choi et al., 2016). In the present study, aged $\mathrm{CCH}$ rats exhibited white matter injury, reflected by a decrease in the IOD measurements in the optic tract (Kluver-Barrera staining). However, no significant effect of $\mathrm{CCH}$ was detected in the corpus callosum in aged ischemic rats. In line, it has been demonstrated that the optic nerve and optic tract are the most vulnerable structures that are affected by $\mathrm{CCH}$ (Wakita et al., 2002) because they receive blood supplies from carotid circulation via the ophthalmic artery, anterior cerebral artery, and distant vertebral circulation (Takamatsu et al., 1984). Such vascular pathways are affected using the 4-VO/ICA model of $\mathrm{CCH}$. Although the behavioral consequences of white matter pathology in aged $\mathrm{CCH}$ rats are still unclear, a link has been suggested between white matter injury and cognitive impairments in the conventional radial maze in CCH mice (Shibata et al., 2007) and in the water maze test in $\mathrm{CCH}$ rats (Choi et al., 2016). Moreover the NOTCH3 gene is linked to white matter injury in humans, and ischemic NOTCH3 knockout mice performed worse than wildtype controls in the novel object recognition task (Blasi et al., 2014).

Neuroinflammation has been accepted as a key pathophysiology of white matter injury in animal models of CCH (Choi et al., 2016). Preserving white matter integrity could enhance the precise and efficient transmission of neuronal signals between different brain areas and result in functional recovery (Han et al., 2016). Roflumilast attenuated cognitive impairments that were induced by $\mathrm{CCH}$ and protected white matter from $\mathrm{CCH}$ injury. These results are supported by early studies that showed that the selective PDE4-I rolipram prevented oligodendrocyte death and leukocyte infiltration that were induced by contusive spinal cord injury in adult rats. Rolipram also improved both descending and ascending long-tract 
axonal conductivity, leading to functional recovery (Beaumont et al., 2009; Costa et al., 2013). We demonstrated in this study that roflumilast favored microglia activation toward M2 phenotyope. M2 microglia have been shown to protect white matter injury by alleviating inflammation, clearing cellular debris and promoting oligodendrocytogenesis and remyelination (Miron et al., 2013). A recent study found that physical exercise has improved the cognitive function of rats with $\mathrm{CCH}$ by alleviating myelin injury and facilitating microglia polarization toward M2 phenotype (Jiang et al., 2017). Thus, it is likely that roflumilast protected white matter injury by decreasing local inflammation. Further studies are warranted to confirm the direct effects of roflumilast on microglia polarization in white matter and the underlying mechanisms.

In summary, the present study found that roflumilast increased survival rates, promoted memory recovery, and attenuated white matter injury in aged rats that were subjected to $4 \mathrm{VO} / \mathrm{ICA}$, effects that might be associated to an anti-inflammatory action of roflumilast. These findings suggest that roflumilast may be useful as a pharmacological strategy for improving memory deficits that are induced by $\mathrm{CCH}$.

\section{Conflicts of interest}

The authors declare no conflict of interest, except for Jos Prickaerts who has a proprietary interest in the PDE4 inhibitor roflumilast.

\section{Acknowledgments}

The authors thank Marco Alberto Trombelli for his technical support. This study was supported by Conselho Nacional de Desenvolvimento Científico e Tecnológico (CNPq), CAPES/NUFFIC $1608 / 2010$, Brazil, State university of Maringá, The University of Maastricht and Hasselt University.

\section{References}

Aronowski, J., Samways, E., Strong, R., Rhoades, H.M., Grotta, J.C., 1996. An alternative method for the quantitation of neuronal damage after experimental middle cerebral artery occlusion in rats: analysis of behavioral deficits. J. Cerebr. Blood Flow Metabol. 16, 705-713.

Beaumont, E., Whitaker, C.M., Burke, D.A., Hetman, M., Onifer, S.M., 2009. Effects of rolipram on adult rat oligodendrocytes and functional recovery after contusive cervical spinal cord injury. Neuroscience 163, 985-990.

Bender, A.T., Beavo, J.A., 2006. Cyclic nucleotide phosphodiesterases: molecular regulation to clinical use. Pharmacol. Rev. 58, 488-520.

Benetoli, A., Dutra, A.M., Paganelli, R.A., Senda, D.M., Franzin, S., Milani, H., 2007. Tacrolimus (FK506) reduces hippocampal damage but fails to prevent learning and memory deficits after transient, global cerebral ischemia in rats. Pharmacol. Biochem. Behav. 88 (1), 28-38.

Biffi, A., Bailey, D., Anderson, C.D., Ayres, A.M., Gurol, E.M., Greenberg, S.M., Rosand, J., Viswanathan, A., 2016. Risk factors associated with early vs delayed dementia after intracerebral hemorrhage. JAMA Neurol. 73, 969-976.

Blasi, F., Wei, Y., Balkaya, M., Tikka, S., Mandeville, J.B., Waeber, C., Ayata, C., Moskowitz, M.A., 2014. Recognition memory impairments after subcortical white matter stroke in mice. Stroke 45, 1468-1473.

Block, F., Tondar, A., Schmidt, W., Schwarz, M., 1997. Delayed treatment with rolipram protects against neuronal damage following global ischemia in rats. Neuroreport 8, 3829-3832.

Bolandzadeh, N., Davis, J.C., Tam, R., Handy, T.C., Liu-Ambrose, T., 2012. The association between cognitive function and white matter lesion location in older adults: a systematic review. BMC Neurol. 12, 126.

Boone, K.B., Miller, B.L., Lesser, I.M., Mehringer, C.M., Hill-Gutierrez, E. Goldberg, M.A., Berman, N.G., 1992. Neuropsychological correlates of whitematter lesions in healthy elderly subjects. Arch. Neurol. 49, 549-554.

Braun, N.N., Reutiman, T.J., Lee, S., Folsom, T.D., Fatemi, S.H., 2007. Expression of phosphodiesterase 4 is altered in the brains of subjects with autism. Neuroreport 18, 1841-1844.

Burke, S.N., Barnes, C.A., 2006. Neural plasticity in the ageing brain. Nat. Rev Neurosci. 7, 30-40.

Calabrese, F., Guidotti, G., Racagni, G., Riva, M.A., 2013. Reduced neuroplasticity in aged rats: a role for the neurotrophin brain-derived neurotrophic factor. Neurobiol. Aging 34 (12), 2768-2776.
Cheng, Y.F., Wang, C., Lin, H.B., Li, Y.F., Huang, Y., Xu, J.P., Zhang, H.T., 2010. Inhibition of phosphodiesterase-4 reverses memory deficits produced by Abeta25-35 or Abeta1-40 peptide in rats. Psychopharmacology 212, 181-191.

Cherry, J.D., Olschowka, J.A., O'Banion, M.K., 2014. Neuroinflammation and M2 microglia: the good, the bad, and the inflamed. J. Neuroinflammation 3 (11), 98.

Cho, K.O., La, H.O., Cho, Y.J., Sung, K.W., Kim, S.Y., 2006. Minocycline attenuates white matter damage in a rat model of chronic cerebral hypoperfusion. J. Neurosci. Res. 83, 285-291.

Choi, J.H., Yoo, K.Y., Lee, C.H., Park, J.H., Yan, B.C., Kwon, S.H., Seo, J.Y., Cho, J.H., Hwang, I.K., Won, M.H., 2012. Comparison of neurogenesis in the dentate gyrus between the adult and aged gerbil following transient global cerebral ischemia. Neurochem. Res. 37 (4), 802-810.

Choi, B.R., Kim, D.H., Back, D.B., Kang, C.H., Moon, W.J., Han, J.S., Choi, D.H., Kwon, K.J., Shin, C.Y., Kim, B.R., Lee, J., Han, S.H., Kim, H.Y., 2016. Characterization of white matter injury in a rat model of chronic cerebral hypoperfusion. Stroke 47 (2), 542-547.

Conti, M., Beavo, J., 2007. Biochemistry and physiology of cyclic nucleotide phosphodiesterases: essential components in cyclic nucleotide signaling. Annu. Rev. Biochem. 76, 481-511.

Costa, L.M., Pereira, J.E., Filipe, V.M., Magalhaes, L.G., Couto, P.A., GonzaloOrden, J.M., Raimondo, S., Geuna, S., Mauricio, A.C., Nikulina, E., Filbin, M.T., Varejao, A.S., 2013. Rolipram promotes functional recovery after contusive thoracic spinal cord injury in rats. Behav. Brain Res. 243, 66-73.

De la Torre, J.C., 2009. Cerebrovascular and cardiovascular pathology in Alzheimer's disease. Int. Rev. Neurobiol. 84, 35-48.

de la Tremblaye, P.B., Plamondon, H., 2012. Impaired conditioned emotional response and object recognition are concomitant to neuronal damage in the amygdala and neurodegeneration and memory impairment following the 4vessel occlusion/internal carotid artery model of chronic cerebral hypoperfusion in middle-aged rats. Behav. Brain Res. 15229 (2), 340-348.

Dixon, W.J., 1959. Analyses of extreme values. Ann. Math. Stat. 21, 488-506.

Farkas, E., Donka, G., de Vos, R.A., Mihaly, A., Bari, F., Luiten, P.G., 2004. Experimental cerebral hypoperfusion induces white matter injury and microglial activation in the rat brain. Acta Neuropathol. 108, 57-64.

Ferreira, E.D.F., Romanini, C.V., Mori, M.A., de Oliveira, R.M., Milani, H., 2011. Middleaged, but not young, rats develop cognitive impairment and cortical neurodegeneration following the four-vessel occlusion/internal carotid artery model of chronic cerebral hypoperfusion. Eur. J. Neurosci. 34, 1131-1140.

Ferreira, E.D.F., Romanini, C.V., Cypriano, P.E., Weffort de Oliveira, R.M., Milani, H., 2013. Sildenafil provides sustained neuroprotection in the absence of learning recovery following the 4-vessel occlusion/internal carotid artery model of chronic cerebral hypoperfusion in middle-aged rats. Brain Res. Bull. 90, 58-65.

Frey, U., Huang, Y.Y., Kandel, E.R., 1993. Effects of cAMP simulate a late stage of LTP in hippocampal CA1 neurons. Science 260, 1661-1664.

Garcia, A.M., Martinez, A., Gil, C., 2016. Enhancing cAMP levels as strategy for the treatment of neuropsychiatric disorders. Curr. Top. Med. Chem. 16 (29), 3527-3535.

Godinho, J., de Oliveira, J.N., Ferreira, E.D., Zaghi, G.G., Bacarin, C.C., de Oliveira, R.M., Milani, H., 2015. Cilostazol but not sildenafil prevents memory impairment after chronic cerebral hypoperfusion in middle-aged rats. Behav. Brain Res. 283, $61-68$.

Gong, B., Vitolo, O.V., Trinchese, F., Liu, S., Shelanski, M., Arancio, O., 2004. Persistent improvement in synaptic and cognitive functions in an Alzheimer mouse model after rolipram treatment. J. Clin. Invest. 114, 1624-1634.

Gonzalez-Garcia, C., Bravo, B., Ballester, A., Gomez-Perez, R., Eguiluz, C., Redondo, M., Martinez, A., Gil, C., Ballester, S., 2013. Comparative assessment of PDE 4 and 7 inhibitors as therapeutic agents in experimental autoimmune encephalomyelitis. Br. J. Pharmacol. 170, 602-613.

Greenhalgh, A.D., Passos Dos Santos, R., Zarruk, J.G., Salmon, C.K., Kroner, A., David, S., 2016. Arginase-1 is expressed exclusively by infiltrating myeloid cells in CNS injury and disease. Brain Behav. Immun. 56, 61-67.

Haffner, I., Teupser, D., Holdt, L.M., Ernst, J., Burkhardt, R., Thiery, J., 2008. Regulation of arginase-1 expression in macrophages by a protein kinase A type I and histone deacetylase dependent pathway. J. Cell Biochem. 103 (2), 520-527.

Han, Z., Ma, Y., Gong, G., Huang, R., Song, L., Bi, Y., 2016. White matter pathway supporting phonological encoding in speech production: a multi-modal imaging study of brain damage patients. Brain Struct. Funct. 221 (1), 577-589.

Harry, G.J., 2013. Microglia during development and aging. Pharmacol. Ther. 139 (3), 313-326.

Heckman, P.R., Blokland, A., Ramaekers, J., Prickaerts, J., 2015. PDE and cognitive processing: beyond the memory domain. Neurobiol. Learn. Mem. 119, 108-122.

Hu, X., Li, P., Guo, Y., Wang, H., Leak, R.K., Chen, S., Gao, Y., Chen, J., 2012. Microglia/ macrophage polarization dynamics reveal novel mechanism of injury expansion after focal cerebral ischemia. Stroke 43 (11), 3063-3070.

Ihara, M., Tomimoto, H., Kinoshita, M., Oh, J., Noda, M., Wakita, H., Akiguchi, I., Shibasaki, H., 2001. Chronic cerebral hypoperfusion induces MMP-2 but not MMP-9 expression in the microglia and vascular endothelium of white matter. J. Cerebr. Blood Flow Metabol. 21, 828-834.

Imanishi, T., Sawa, A., Ichimaru, Y., Miyashiro, M., Kato, S., Yamamoto, T., Ueki, S., 1997. Ameliorating effects of rolipram on experimentally induced impairments of learning and memory in rodents. Eur. J. Pharmacol. 321, 273-278.

Jabaris, S.G., Sumathy, H., Kumar, R.S., Narayanan, S., Thanikachalam, S., Babu, C.S., 2015a. Effects of rolipram and roflumilast, phosphodiesterase-4 inhibitors, on hypertension-induced defects in memory function in rats. Eur. J. Pharmacol. 746, 138-147. 
Jabaris, S.S., Sumathy, H., Girish, R., Narayanan, S., Sugumar, M., Saravana Babu, C., Thanikachalam, S., Thanikachalam, M., 2015b. Phosphodiesterase-4 inhibitors ameliorates cognitive deficits in deoxycorticosterone acetate induced hypertensive rats via CAMP/CREB signaling system. Brain Res. 1622, 279-291.

Jiang, T., Zhang, L., Pan, X., Zheng, H., Chen, X., Li, L., Luo, J., Hu, X., 2017. Physical Exercise improves cognitive function together with microglia phenotype modulation and remyelination in chronic cerebral hypoperfusion. Front. Cell. Neurosci. 11, 400-404.

Koellhoffer, E.C., McCullough, L.D., Ritzel, R.M., 2017. Old maids: Aging and its impact on microglia function. Int. J. Mol. Sci. 518 (4), E769.

Lee, I., Kesner, R.P., 2003. Time-dependent relationship between the dorsal hippocampus and the prefrontal cortex in spatial memory. J. Neurosci. 23 (4), 1517-1523, 15.

Lee, J.H., Park, S.Y., Shin, Y.W., Hong, K.W., Kim, C.D., Sung, S.M., Kim, K.Y., Lee, W.S., 2006. Neuroprotection by cilostazol, a phosphodiesterase type 3 inhibitor, against apoptotic white matter changes in rat after chronic cerebral hypoperfusion. Brain Res. 1082, 182-191.

Li, Y.F., Huang, Y., Amsdell, S.L., Xiao, L., O'Donnell, J.M., Zhang, H.T., 2009. Antidepressant- and anxiolytic-like effects of the phosphodiesterase-4 inhibitor rolipram on behavior depend on cyclic AMP response element binding proteinmediated neurogenesis in the hippocampus. Neuropsychopharmacology 34, 2404-2419.

Li, L.X., Cheng, Y.F., Lin, H.B., Wang, C., Xu, J.P., Zhang, H.T., 2011. Prevention of cerebral ischemia-induced memory deficits by inhibition of phosphodiesterase-4 in rats. Metab. Brain Dis. 26, 37-47.

Loane, D.J., Kumar, A., 2016. Microglia in the TBI brain: the good, the bad, and the dysregulated. Exp. Neurol. 275, 316-327.

Luckhaus, C., Grass-Kapanke, B., Blaeser, I., Ihl, R., Supprian, T., Winterer, G., Zielasek, J., Brinkmeyer, J., 2008. Quantitative EEG in progressing vs stable mild cognitive impairment (MCI): results of a 1-year follow-up study. Int. J. Geriatr. Psychiatr. 23, 1148-1155.

MacDonald, E., Van der Lee, H., Pocock, D., Cole, C., Thomas, N., VandenBerg, P.M., Bourtchouladze, R., Kleim, J.A., 2007. A novel phosphodiesterase type 4 inhibitor, HT-0712, enhances rehabilitation-dependent motor recovery and cortical reorganization after focal cortical ischemia. Neurorehabilitation Neural Repair 21, 486-496.

Menniti, F.S., Faraci, W.S., Schmidt, C.J., 2006. Phosphodiesterases in the CNS: targets for drug development. Nat. Rev. Drug Discov. 5, 660-670.

Miron, V.E., Boyd, A., Zhao, J.W., Yuen, T.J., Ruckh, J.M., Shadrach, J.L., van Wijngaarden, P., Wagers, A.J., Williams, A., Franklin, R.J.M., Ffrench-Constant, C. 2013. M2 microglia and macrophages drive oligodendrocyte differentiation during CNS remyelination. Nat Neurosci 16 (9), 1211-1218.

Nagakura, A., Niimura, M., Takeo, S., 2002. Effects of a phosphodiesterase IV inhibitor rolipram on microsphere embolism-induced defects in memory function and cerebral cyclic AMP signal transduction system in rats. Br. J. Pharmacol, $135,1783-1793$.

Neto, C.J., Paganelli, R.A., Benetoli, A., Lima, K.C., Milani, H., 2005. Permanent, 3stage, 4-vessel occlusion as a model of chronic and progressive brain hypoperfusion in rats: a neurohistological and behavioral analysis. Behav. Brain Res. $160,312-322$

Nunes Santiago, A., Dias Fiuza Ferreira, E., Weffort de Oliveira, R.M., Milani, H., 2018 Cognitive neurohistological and mortality outcomes following the four-vessel occlusion/internal carotid artery model of chronic cerebral hypoperfusion: the impact of diabetes and aging. Behav. Brain Res. 26, 169-178, 339.

O'Donnell, J.M., Zhang, H.T., 2004. Antidepressant effects of inhibitors of cAMP phosphodiesterase (PDE4). Trends Pharmacol. Sci. 25, 158-163.

O'Meara, R.W., Ryan, S.D., Colognato, H., Kothary, R., 2011. Derivation of enriched oligodendrocyte cultures and oligodendrocyte/neuron myelinating co-cultures from post-natal murine tissues. JoVE : JoVE 2011 (54).

Paganelli, R.A., Benetolli, A., Lima, K.C., Cestari-Junior, L.A., Favero Filho, L.A., Milani, H., 2004. A novel version of the 8-arm radial maze: effects of cerebral ischemia on learning and memory. J. Neurosci. Meth. 132, 9-18.

Paxinos, G., Watson, C. (Eds.), 1997. The Rat Brain in Sterotaxic Coordinates, 3a ed. Editora Academic Press, San Diego, CA, USA.

Peng, S., Sun, H., Zhang, X., Liu, G., Wang, G., 2014. Effects of selective phosphodiesterases-4 inhibitors on learning and memory: a review of recent research. Cell Biochem. Biophys. 70, 83-85.

Pereira, F.M., Ferreira, E.D., de Oliveira, R.M., Milani, H., 2011. Time-course of perirhinal cortex in middle-aged ischemic rats. Behav, Brain Res. 219 (2), 227-233.

Prickaerts, J., de Vente, J., Honig, W., Steinbusch, H.W., Blokland, A., 2002. cGMP, but not cAMP, in rat hippocampus is involved in early stages of object memory consolidation. Eur. J. Pharmacol. 436, 83-87.

Rabe, K.F., 2011. Update on roflumilast, a phosphodiesterase 4 inhibitor for the treatment of chronic obstructive pulmonary disease. Br. J. Pharmacol. 163 53-67.

Ricciarelli, R., Fedele, E., 2015. Phosphodiesterase 4D: an enzyme to remember. Br. J. Pharmacol. 172, 4785-4789.

Rock, E.M., Benzaquen, J., Limebeer, C.L., Parker, L.A., 2009. Potential of the rat model of conditioned gaping to detect nausea produced by rolipram, a phosphodiesterase-4 (PDE4) inhibitor. Pharmacol. Biochem. Behav. 91, 537-541.

Romanini, C.V., Ferreira, E.D.F., Bacarin, C.C., Verussa, M.H., de Oliveira, R.M.W., Milani, H., 2013. Neurohistological and behavioral changes following the fourvessel occlusion/internal carotid artery model of chronic cerebral hypoperfusion: comparison between normotensive and spontaneously hypertensive rats. Behav. Brain Res. 252, 214-221.

Rose, G.M., Hopper, A., De Vivo, M., Tehim, A., 2005. Phosphodiesterase inhibitors for cognitive enhancement. Curr. Pharmaceut. Des. 11, 3329-3334.

Rutten, K., Prickaerts, J., Blokland, A., 2006. Rolipram reverses scopolamine-induced and time-dependent memory deficits in object recognition by different mechanisms of action. Neurobiol. Learn. Mem. 85, 132-138.

Rutten, K., Prickaerts, J., Hendrix, M., van der Staay, F.J., Sik, A., Blokland, A., 2007 Time-dependent involvement of cAMP and cGMP in consolidation of object memory: studies using selective phosphodiesterase type 2, 4 and 5 inhibitors. Eur. J. Pharmacol. 558, 107-112.

Sasaki, T., Kitagawa, K., Omura-Matsuoka, E., Todo, K., Terasaki, Y., Sugiura, S. Hatazawa, J., Yagita, Y., Hori, M., 2007. The phosphodiestrase rolipram promotes survival of newborn hippocampal neurons after ischemia. Stroke 38 (5) 1597-1605.

Seif el Nasr, M., Nuglisch, J., Krieglstein, J., 1992. Prevention of ischemia-induced cerebral hypothermia by controlling the environmental temperature. J. Pharmacol. Toxicol. Methods 27 (1), 23-26.

Shetty, A.K., Hattiangady, B., Rao, M.S., Shuai, B., 2011. Deafferentation enhances neurogenesis in the young and middle aged hippocampus but not in the aged hippocampus. Hippocampus 21 (6), 631-646.

Shibata, M., Yamasaki, N., Miyakawa, T., Kalaria, R.N., Fujita, Y., Ohtani, R., Ihara, M., Takahashi, R., Tomimoto, H., 2007. Selective impairment of working memory in a mouse model of chronic cerebral hypoperfusion. Stroke 38, 2826-2832.

Soares, L.M., De Vry, J., Steinbusch, H.W., Milani, H., Prickaerts, J., Weffort de Oliveira, R.M., 2016. Rolipram improves cognition, reduces anxiety- and despair-like behaviors and impacts hippocampal neuroplasticity after transient global cerebral ischemia. Neuroscience 326, 69-83.

Son, H., Lu, Y.F., Zhuo, M., Arancio, O., Kandel, E.R., et al., 1998. The specific role of cGMP in hippocampal LTP. Learning \& Memory 5: 231-245. lved in early stages of object memory consolidation. Eur. J. Pharmacol. 436, 83-87.

Takamatsu, J., Hirano, A., Levy, D., Henkind, P., 1984. Experimental bilateral carotid artery occlusion: a study of the optic nerve in the rat. Neuropathol. Appl. Neurobiol. 10, 423-428.

Tashkin, D.P., 2014. Roflumilast: the new orally active, selective phophodiesterase-4 inhibitor, for the treatment of COPD. Expet Opin. Pharmacother. 15, 85-96.

Van Duinen, M.A., Sambeth, A., Heckman, P.R.A., Smit, S., Tsai, M., Lahu, G., Uz, T., Blokland, A., Prickaerts, J., 2018. Acute administration of roflumilast enhances immediate recall of verbal word memory in healthy young adults. Neuropharmacology 131, 31-38.

Vanmierlo, T., Creemers, P., Akkerman, S., van Duinen, M., Sambeth, A., De Vry, J., Uz, T., Blokland, A., Prickaerts, J., 2016. The PDE4 inhibitor roflumilast improves memory in rodents at non-emetic doses. Behav. Brain Res. 303, 26-33.

Wakita, H., Tomimoto, H., Akiguchi, I., Matsuo, A., Lin, J.X., Ihara, M., McGeer, P.L., 2002. Axonal damage and demyelination in the white matter after chronic cerebral hypoperfusion in the rat. Brain Res. 924, 63-70.

Watanabe, T., Zhang, N., Liu, M., Tanaka, R., Mizuno, Y., Urabe, T., 2006. Cilostazol protects against brain white matter damage and cognitive impairment in a rat model of chronic cerebral hypoperfusion. Stroke 37, 1539-1545.

Xiong, X., Barreto, G.E., Xu, L., Ouyang, Y.B., Xie, X., Giffard, R.G., 2011. Increased brain injury and worsened neurological outcome in interleukin-4 knockout mice after transient focal cerebral ischemia. Stroke 42 (7), 2026-2032.

Zhang, H.T., O'Donnell, J.M., 2000. Effects of rolipram on scopolamine-induced impairment of working and reference memory in the radial-arm maze tests in rats. Psychopharmacology 150, 311-316.

Zhao, L., Gong, N., Liu, M., Pan, X., Sang, S., Sun, X., Yu, Z., Fang, Q., Zhao, N., Fei, G., Jin, L., Zhong, C., Xu, T., 2014. Beneficial synergistic effects of microdose lithium with pyrroloquinoline quinone in an Alzheimer's disease mouse model. Neurobiol. Aging 35, 2736-2745.

Zhuo, Y., Guo, H., Cheng, Y., Wang, C., Wang, C., Wu, J., Zou, Z., Gan, D., Li, Y., Xu, J., 2016. Inhibition of phosphodiesterase-4 reverses the cognitive dysfunction and oxidative stress induced by Abeta25-35 in rats. Metab. Brain Dis. 31, 779-791. 